\title{
ELECTROPHYSIOLOGICAL MECHANISMS OF KAINIC ACID- INDUCED EPILEPTIFORM ACTIVITY IN THE RAT HIPPOCAMPAL SLICE ${ }^{1}$
}

\author{
ROBERT S. FISHER ${ }^{2}$ AND BRADLEY E. ALGER
}

Department of Physiology, University of Maryland School of Medicine, Baltimore, Maryland 21201

Received August 29, 1983; Revised December 28, 1983; Accepted January 4, 1984

\begin{abstract}
Depression of GABA-mediated IPSPs has been proposed to be a crucial factor in the onset of epileptiform activity in most models of epilepsy. To test this idea, we studied epileptiform activity induced by bath application of the excitatory neurotoxin kainic acid (KA) in the rat hippocampal slice. Repetitive field potential firing, spontaneous or evoked, occurred during exposure to KA. Intracellular records from $52 \mathrm{CA} 1$ pyramidal cells during changes from control saline to saline containing $1 \mu \mathrm{M} \mathrm{KA}$ indicated that KA depolarized cells an average of about $5 \mathrm{mV}$ and caused a $15 \%$ decrease in input resistance. Action potentials and current-induced burst afterhyperpolarizations did not change significantly. In several cells the tonic effects of KA were preceded by a transient phase of sporadic, spontaneous depolarizations of 2 to $10 \mathrm{mV}$ and 50 to $200 \mathrm{msec}$ duration. These phasic depolarizations were blocked by hyperpolarization.

The major effect of $1 \mu \mathrm{M} \mathrm{KA}$ was a depression of synaptic potentials. Initially, KA depressed fast GABA-mediated IPSPs and slow, non-GABA-mediated late hyperpolarizing potentials to $23 \%$ and $40 \%$ of control values, respectively. IPSP depression correlated closely with onset of burst potential firing in response to synaptic stimulation. Similar observations were made on six cells from the $\mathrm{CA} 2 / 3$ region, although these cells were affected by lower doses of KA.

The mechanism of IPSP depression was studied by using $\mathrm{KCl}$-filled electrodes to invert spontaneous IPSPs and make them readily visible. In nine CA1 cells the rate and amplitude of spontaneous IPSPs transiently increased but then decreased in conjunction with evoked IPSP depression. Possible KA effects on postsynaptic GABA responses were investigated by applying GABA locally to cells. KA did not significantly affect GABA responses. Prolonged exposure of CA1 cells to KA in doses of $1 \mu \mathrm{M}$ or higher depressed intracellularly and extracellularly recorded EPSPs and all field potential activity. This depression was not apparently due to depolarization block in CA1, however.

We conclude that KA induces epileptiform activity in hippocampus principally by a presynaptic block of IPSP pathways.
\end{abstract}

Recent studies of epileptiform activity induced by bicuculline (Schwartzkroin and Prince, 1980), picrotoxin (Alger and Nicoll, 1980a), or penicillin (Wong and Prince, 1979; Dingledine and Gjerstad, 1980) in the in vitro hippocampal slice preparation have shown that reduction of pyramidal cell IPSPs is closely associated with the onset of repetitive cell firing and epileptiform extracellular field potential discharges. To test whether disinhibition is a necessary factor in generation of epi-

\footnotetext{
${ }^{1}$ This work was supported by National Institutes of Health Grant NS17539 and a McKnight Foundation Scholar's Award (B. E. A.) and by TIDA 5K07NS00697 (R. S. F.)

${ }^{2}$ To whom reprint requests should be sent, at his current address: Department of Neurology, Meyer Building, Room 5-109, Johns Hopkins Hospital, Baltimore MD 21205.
}

leptiform discharges, we have examined the electrophysiology of kainic acid (KA)-induced discharges in the rat hippocampal slice.

$\mathrm{KA}$ is a conformationally rigid analogue of glutamic acid (Kizer et al., 1978), a putative excitatory neurotransmitter in the hippocampus (Nadler et al., 1976). In moderate doses it induces behavioral and electroencephalographic seizures analogous to clinical complex partial seizures (Nadler, 1981), whereas in high doses it causes "toxic" changes in cells (McGeer et al., 1978). Excitatory effects of KA were first described for rat neocortical cells (Shinozaki and Konishi, 1970). Subsequently KA has been shown to excite motoneurons (Biscoe et al., 1976; Engberg et al., 1978), dorsal root fibers (Constanti and Nistri, 1976; Evans, 1980), Renshaw interneurons (Johnston et al., 1974), rat thalamic neurons (Hall et al., 1979), 
and hippocampal pyramidal cells (De Montigny and Tardif, 1981). The electrophysiological mechanisms of neuronal excitation are poorly understood. The principal action of $\mathrm{KA}$ on invertebrate neurons is a potentiation of glutamate-induced depolarizations (Shinozaki and Shibuya, 1974; Daoud and Usherwood, 1975; Constanti and Nistri, 1976). In contrast, iontophoretic application of KA to vertebrate spinal cord directly produces large and often irreversible depolarizations (Biscoe et al., 1976; Constanti and Nistri, 1976; Ault et al., 1980; Evans, 1980 ), by a mechanism which decreases input resistance (Engberg et al., 1978) and depends upon the presence of extracellular sodium (Evans et al., 1977; MacDonald and Porietis, 1982).

The hippocampus is especially susceptible to the epileptogenic effects of KA (Ben-Ari, et al., 1981; 7aczek et al., 1981). Hippocampal field potential studies have suggested that the epileptogenicity is due either to an augmentation in excitation (Lothman et al., 1981; Collingridge et al., 1983), a depression of inhibition (Sloviter and Damiano, 1981), or perhaps to both. Intracellular recordings from hippocampal cells in the in vitro slice preparation have indicated that $\mathrm{KA}$ induces membrane depolarizations (Robinson and Deadwyler, 1981; Westbrook and Lothman, 1983), but synaptic potentials have not been analyzed in detail. Therefore, it has remained open whether or not KA might induce epileptiform activity in vertebrate CNS by direct excitation not involving disinhibition.

To evaluate KA effects on synaptic potentials in hippocampus, two technical requirements should be met. First, synaptic potentials should be measured directly with intracellular techniques. Second, drug-induced effects on synaptic potentials should be reversible, if possible, to minimize complications due to nonspecific effects. We have studied synaptic potentials in individual hippocampal pyramidal cells before, during, and after bath application of KA. We find that KA decreases synaptic inhibition and that the major component of this effect is exerted at a presynaptic locus.

\section{Materials and Methods}

Experiments were performed on $400-\mu \mathrm{m}$ thick slices from hippocampi of 175 to 250 -gm adult male SpragueDawley rats using standard techniques (Langmoen and Andersen, 1981). After dissection, single slices were transferred to a submersion-type recording chamber $(\mathrm{Ni}$ coll and Alger, 1981a) and set gently on a nylon net. The standard saline solution consisted of (millimolar): $\mathrm{NaCl}$, $122.6 ; \mathrm{KCl}, 5.4$ (in the first few experiments $3.5 \mathrm{~mm}$ was used); $\mathrm{MgSO}_{4}, 2.0 ; \mathrm{CaCl}_{2}, 2.5 ; \mathrm{NaH}_{2} \mathrm{PO}_{4}, 1.2 ; \mathrm{NaHCO}_{3}$, 26.2; glucose, 10. Solutions of KA were prepared fresh on the day of each experiment and were added to the saline to achieve concentrations of 0.3 to $10 \mu \mathrm{M}$. These concentrations did not affect final $\mathrm{pH}$. In preliminary experiments we confirmed the dose-response relationship for KA determined by Westbrook and Lothman (1983). We also observed that prolonged perfusion with KA lead to increasingly marked depressive effects (e.g., see Fig. 5). Lacking a direct measure of actual drug concentration in the extracellular space, we were unable to determine if this was attributable to a time or dose dependency of the drug effect. To focus on the epileptogenic effects, which always preceded the depression, we selected a KA dose of $1 \mu \mathrm{M}$ so as to achieve relatively marked, reproducible, and reversible effects in conjunction with a 20-min perfusion. In some experiments, 60 $\mu \mathrm{M}$ picrotoxin or $1 \mu \mathrm{M}$ tetrodotoxin (TTX) was used to block evoked IPSPs. Salines were bubbled with $95 \% \mathrm{O}_{2}$ and $5 \% \mathrm{CO}_{2}$ and were gravity-fed through the chamber at a rate of $0.3 \mathrm{ml} / \mathrm{min}$. Solutions were switched by means of a stopcock close to the chamber. Dead space was small, so that steady-state drug concentrations in the chamber were achieved within 5 min of switching solutions. Temperature was regulated to 30 to $32^{\circ} \mathrm{C}$.

Electrophysiological technique. Intracellular potentials were recorded from pyramidal neurons in the midportion of CA 1 and in a few cells from CA $2 / 3$ during control, experimental perfusion, and wash periods. (Since it is difficult to distinguish between regions CA2 and CA3 near their common border, we refer to cells from this area as from "CA2/3," cf. Wong and Traub, 1983.) Microelectrodes were pulled from fiber-filled glass, with final impedance measuring 50 to 100 megohms at $135 \mathrm{~Hz}$ in $3 \mathrm{M} \mathrm{KCl}$. Intracellular pipettes were usually filled with potassium methylsulfate $\left(\mathrm{KCH}_{3} \mathrm{SO}_{4}\right)$ or, where specified, with $3 \mathrm{M} \mathrm{KCl}$. Conventional intracellular recording techniques were used. AC-coupled extracellular field potentials were recorded with broken-tip glass pipettes containing $1 \mathrm{M} \mathrm{NaCl}$ and were filtered at 3 to $1000 \mathrm{~Hz}$. All electrodes were positioned in stratum (s.) pyramidale, $\mathrm{s}$. radiatum, or fimbria. Concentric bipolar stainless steel wires were used to deliver 10 to $50-\mu$ sec constant-voltage stimuli to hippocampal fiber systems in s. radiatum or alveus. Electrical potentials were viewed on-line oscilloscopically or via a rectilinear chart recorder (Gould 2200) and also stored on FM tape (Hewlett-Packard, bandpass 0 to $5000 \mathrm{~Hz}$ ). Only neurons with resting potentials in excess of $-50 \mathrm{mV}$, stable for at least 30 min prior to any experimental manipulations, were exposed to KA.

Experiments were done on 82 slices from 52 rats. Intracellular records were taken from $52 \mathrm{CA} 1$ pyramidal cells, 6 CA2/3 pyramidal cells, and 2 presumed glia; 34 of the CA1 pyramidal cells showed at least partial reversal of KA effects on synaptic potentials (see below). These $34 \mathrm{CA} 1$ cells and $5 \mathrm{CA} 2 / 3$ cells were analyzed in detail. The mean resting potential for the CA1 neurons was $72.8 \pm 10.4 \mathrm{mV}$, the mean input resistance was $51 \pm$ 12 megohms, and the mean action potential amplitude was $96 \pm 18 \mathrm{mV}$. In the following, unless otherwise noted, "cell" refers to one of these CA1 pyramidal neurons.

Current-voltage plots were constructed by plotting the maximal change in membrane voltage produced by an injection of 100 -msec constant-current pulses through a balanced bridge circuit.

Local drug application. GABA was applied iontophoretically by a single-barreled pipette (impedance 5 to 20 megohms) containing $1 \mathrm{M}$ GABA in normal saline, with $\mathrm{pH}$ adjusted to 4.0 with $\mathrm{HCl}$. Iontophoretic pulses were delivered by a WPI 161 iontophoresis unit. Holding currents were 0 to $20 \mathrm{nA}$, and ejection currents ranged from 5 to $100 \mathrm{nA}$. During the control period of the experiments, the iontophoretic pipette was positioned as close to the intracellular microelectrode as possible and was then lowered by a remote drive in $10-\mu \mathrm{m}$ steps until 
the maximal hyperpolarizing response was observed. With high ejection currents a secondary depolarizing component of the response could be elicited, and current was decreased to minimize this depolarizing current. The resting potential of some of the cells was very close to the IPSP equilibrium potential (about $-75 \mathrm{mV}$ ), and in these cells iontophoretic pulses were sometimes delivered with the membrane potential depolarized by DC injection through the bridge circuit. Control and test period base line membrane potential levels were always matched closely. After initial positioning of the iontophoresis pipette, neither the pipette nor the iontophoresis current was changed.

Pressure ejection controls were performed with a $\mathrm{Pi}$ cospritzer (General Valve Corp.) and extracellular pipettes containing $1 \mathrm{mM}$ GABA in normal saline ( $\mathrm{pH}$ was neutral). Pressure pulses ranged from 10 to 40 psi in magnitude and 20 to $200 \mathrm{msec}$ in duration.

Extracellular potassium concentration measurements. Potassium-sensitive microelectrodes were fabricated from single-harreled fiber-filled glass tubing, pulled, and then broken to $5-\mu \mathrm{m}$ tip diameters. Electrodes were siliconized by holding the tips in vapor from evaporating dimethyldichlorosilane for $45 \mathrm{sec}$ and then baking at $95^{\circ} \mathrm{F}$ for $1 \mathrm{hr}$. Dow-Corning ion exchange resin was suctioned into the electrode tip, and the electrode was then back-filled with $0.5 \mathrm{M} \mathrm{KCl}$. Final impedances ranged from 100 to 200 megohms. Signals from this electrode were recorded differentially with respect to an extracellular field electrode in s. pyramidale, within $100 \mu \mathrm{m}$ of the potassium electrode. Before and after the experiment, the electrodes were calibrated by immersion in solutions of normal saline containing $3,5,7,10,30$, and $50 \mathrm{~mm}$ $\mathrm{KCl}$. Data were accepted only from electrodes whose calibration curves did not change and whose slopes were approximately $50 \mathrm{mV}$ per 10 -fold change in potassium concentration. "Concentration" will be used interchangably with "activity," although it is actually the latter which is measured by ion exchange resins. Calibration curves were unaffected by $\mathrm{KA}$ in concentrations up to 10 $\mu \mathrm{M}$. After each electrode was positioned in s. pyramidale, an interval of 5 min was allowed for equilibration, after which starting extracellular potassium concentration $\left(\left[\mathrm{K}^{+}\right]_{0}\right)$ was assumed to equal the bath concentration of $5.4 \mathrm{~mm}$.

\section{Results}

Epileptiform field activity. Bath application of KA for 5 to $15 \mathrm{~min}$ in concentrations of 0.3 to $1.0 \mu \mathrm{M}$ induced a variety of epileptiform field potentials. Some slices exhibited spontaneous interictal spikes (Fig. 1A) and spontaneous rhythmical field discharges (Fig. $1 B$ ). As documented by Schwartzkroin and Prince (1978) and Wong and Traub (1983) for penicillin-induced bursting and by Lothman and colleagues (1981) for KA-induced bursting, burst activity in CA2/3 preceded and appeared to pace the burst activity in CA1 (Fig. $1 C$ ). Spontaneous bursting in CA1 usually lasted only a few minutes. This decline probably reflected loss of driving from $\mathrm{CA} 2 / 3$ since shocks to $\mathrm{s}$. radiatum remained effective in eliciting CA1 field potential and cell bursting. Spontaneous bursting resumed transiently during the wash period. All slices exposed to $1 \mu \mathrm{M}$ KA reversibly developed multiple population discharges in CA1 in response to a single shock to s. radiatum (Fig. 1D). With exposures longer than 15 min or drug concentrations in excess of $1 \mu \mathrm{M}$, evoked and spontaneous field activity became grossly depressed (discussed below). The transition between epileptiform activity and depression of field potentials sometimes occurred rapidly. All field potential changes were fully reversible by control solution washes of $60 \mathrm{~min}$ or less.

Well defined tonic-clonic electroencephalographic seizures, such as seen in intact hippocampus (Kandel and Spencer, 1961), were not observed.

Effects of KA on passive membrane properties. Exposure of CA1 cells to $0.5 \mu \mathrm{M}$ KA or less did not significantly depolarize the cells (mean and SD of difference $=1.6 \pm$ $5.4 \mathrm{mV} ; n=13 ; p>0.1$; this and all subsequent Student's $t$-tests were two-tailed tests on paired observations), although epileptiform field potentials did occur. One micromolar KA caused an average depolarization of $6 \pm$ $5 \mathrm{mV}(n=21 ; p<0.01)$. It was not always possible to reverse the effects of $1 \mu \mathrm{M} \mathrm{KA}$ on resting membrane potentials, even with up to $60 \mathrm{~min}$ of wash. A subset of cells whose membrane potentials completely returned to base line levels exhibited depolarizations comparable to those of the whole group ( $5 \pm 7 \mathrm{mV} ; n=9)$.

Input resistance of CA1 pyramidal cells, determined by injection of $0.5 \mathrm{nA}$ hyperpolarizing current pulses through a balanced bridge circuit, decreased an average of $15 \%$ during perfusion with $1 \mu \mathrm{M} \mathrm{KA}$ (Fig. $2 A$ ). The decreases, while small, frequently persisted through the wash. A composite current-voltage plot before and during perfusion of five cells with KA (Fig. $2 B$ ) illustrates that the slight degree of the input resistance change would be missed if grouped data alone were examined.

Afterhyperpolarizations following trains of action potentials, induced by direct depolarizing current injections into cells (Alger and Nicoll, 1980a; Hotson and Prince, 1980 ), were not altered by $1 \mu \mathrm{M} \mathrm{KA}$, provided the number of action potentials elicited was held constant (Fig. $2 C$ ).

Effects of $K A$ on active membrane properties. During the experiment the membrane potentials were adjusted to control levels by DC injection prior to an initiation of a test action potential, usually by orthodromic stimulation. KA did not change action potential amplitude (mean difference, $0.2 \pm 5.1 \mathrm{mV} ; n=15 ; p>0.2$ ) or duration (mean difference, $0.11 \pm 0.28$ msec; $n=15$; $p>0.1)$.

In approximately half of the neurons studied, an early and prominent effect of KA was induction of membrane potential instabilities ("bumps"), consisting of spontaneous depolarizations 2 to $10 \mathrm{mV}$ in amplitude and 50 to 200 msec in duration (Fig. 3). Action potentials sometimes originated from the peaks of these depolarizations. In contrast to pyramidal cell EPSPs (Schwartzkroin, 1975), the amplitude of these KA-induced potentials increased with DC depolarization of the membrane potential, and they were abolished with membrane hyperpolarization (Fig. $3 A$ ). In one experiment, bumps were abolished when synaptic transmission and regenerative sodium channels were blocked by $1 \mu \mathrm{M}$ TTX.

In a given neuron, the majority of the bumps occurred asynchronously with the concurrently measured field potential discharges, although when a spontaneous field 

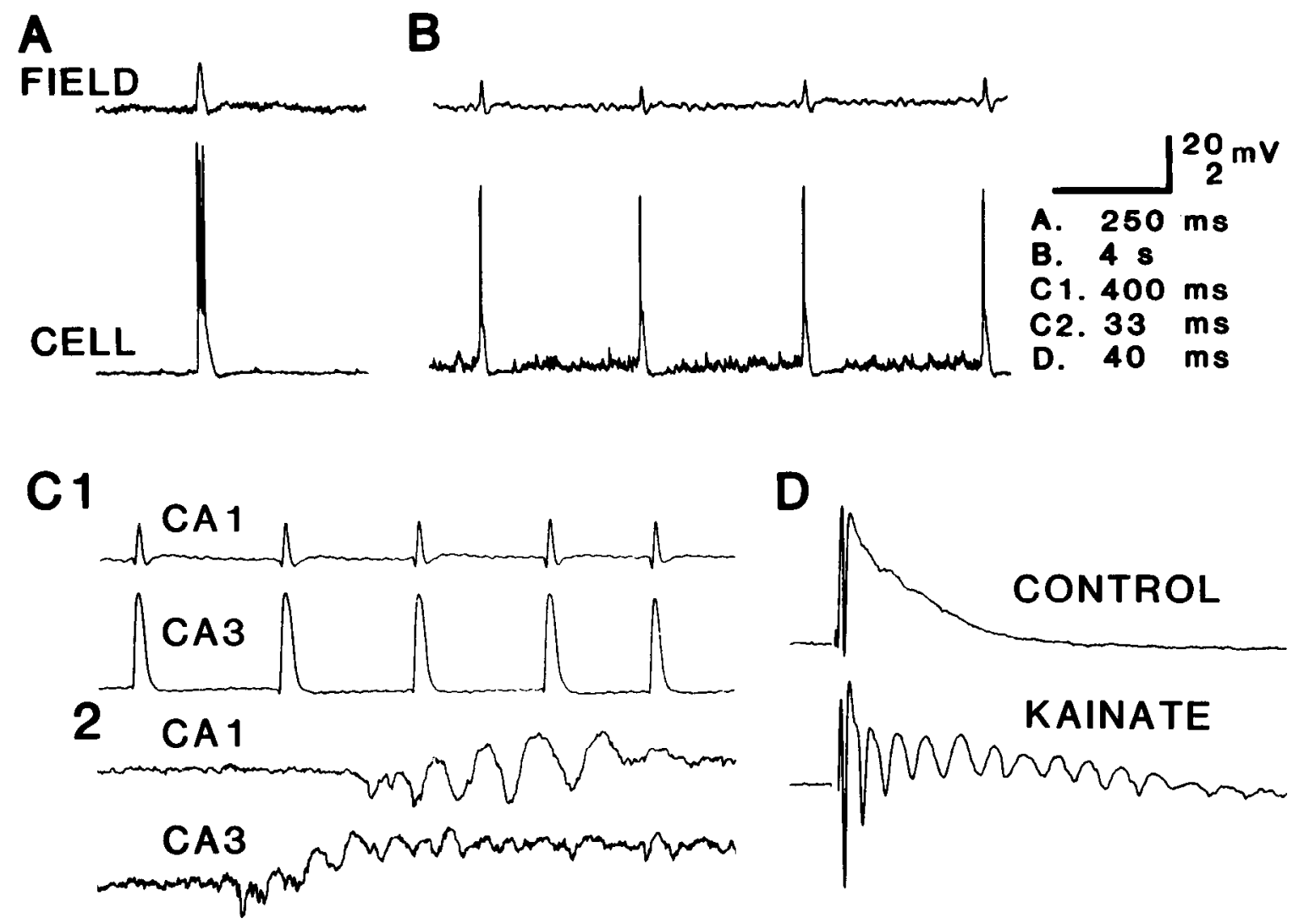

Figure 1. Extracellular (field) and intracellular recordings of epileptiform activity induced by KA. $A$, Spontaneous interictal discharge $5 \mathrm{~min}$ after exposure to $1 \mu \mathrm{M} \mathrm{KA}$. In this and all subsequent figures, action potentials have been truncated by the response time of the chart recorder. $B$, Spontaneous repetitive discharges during perfusion with $1 \mu \mathrm{M}$ KA. $C$, Concurrent field potential records from CA1 and CA2/3 during perfusion with $0.5 \mu \mathrm{M} \mathrm{KA}$. Although bursts appear synchronous in $\mathrm{C} 1$, faster sweep speed of a typical burst in $C 2$ demonstrates that the CA2/3 burst leads the CA1 burst by approximately 30 msec. The different morphologies of the field potentials in $C 1$ and $C 2$ are due to chart recorder response times and filters. $D$, An example of KA-induced repetitive field discharges in CA1. Only one population spike was elicited in the control period in response to an orthodromic stimulus, whereas multiple discharges result from the identical stimulus delivered during perfusion with $1 \mu \mathrm{M}$ KA. $A, B, C$, and $D$ above represent separate experiments. In this and all subsequent figures, stimulus artifacts have been retouched for photographic clarity. Where the site of the artifact is not evident, it is labeled by a vertical arrow (see Figs. 6 to 8 ). Positivity is always up. Voltage calibration is $20 \mathrm{mV}$ for intracellular and $2 \mathrm{mV}$ for extracellular records. Time calibrations are as indicated.

potential did occur a depolarizing event also occurred in the cell (Fig. $3 B$ ). Within 5 to $10 \mathrm{~min}$ of appearance, bumps merged into more or less continuous fluctuations of the base line membrane potential.

Effects of KA on synaptic potentials. During initial exposure to $\mathrm{KA}$, large paroxysmal depolarizations ("bursts"), similar in appearance to the bursts induced by such GABA antagonists as penicillin (Prince, 1978), were elicitable in CA1 cells with suprathreshold orthodromic stimulation. Multiple action potentials arose from the depolarizations and corresponded to multiple population discharges in field recordings (Fig. $4 A$ ). When these bursts were present, EPSPs and IPSPs could not accurately be assessed.

Evoked EPSP amplitudes could be studied in some cells using subthreshold orthodromic stimulation or DC membrane hyperpolarization to block voltage-dependent regenerative conductances. In all instances comparisons were made at the same membrane potential level and with identical orthodromic stimuli in the control, KA, and wash periods. Under these conditions, KA did not affect the amplitude of evoked EPSPs (Fig. 4B). EPSP duration was prolonged, consistent with elimination of inhibitory potentials (e.g., Wong and Prince, 1979) which abbreviated late phases of EPSPs.

At times corresponding to appearance of multiple field potential discharges, the major effect of 0.3 to $1.0 \mu \mathrm{M} \mathrm{KA}$ was a reversible depression of both fast GABAergic IPSPs (Fig. 4C1) and potassium-dependent, slow, nonGABAergic late hyperpolarizing potentials (LHPs) (Fig. 4C2). A decrease of IPSP amplitude was usually evident within $10 \mathrm{~min}$ after starling $1 \mu \mathrm{M}$ KA perfusion and was closely correlated with the appearance of cell bursting and multiple field discharges. In no instance did epileptiform bursting appear with IPSPs at control levels, although projected burst activity from CA3 could appear in CA1 at times when IPSPs in CA1 cells were at 50 to $75 \%$ of control levels. The mean decline of CA1 IPSPs after $10 \mathrm{~min}$ of KA perfusion was to $23 \pm 24 \%$ of the control IPSP amplitude $(n=24)$. During the wash phase, IPSP amplitude recovered to $88 \pm 34 \%$ of control. Both orthodromically and antidromically activated IPSPs were blocked in KA.

LHPs (Nicoll and Alger, 1981b; B. E. Alger, submitted 


\section{A CONTROL KAINATE WASH}

$\underset{(m V)}{E m}-73-71-73$
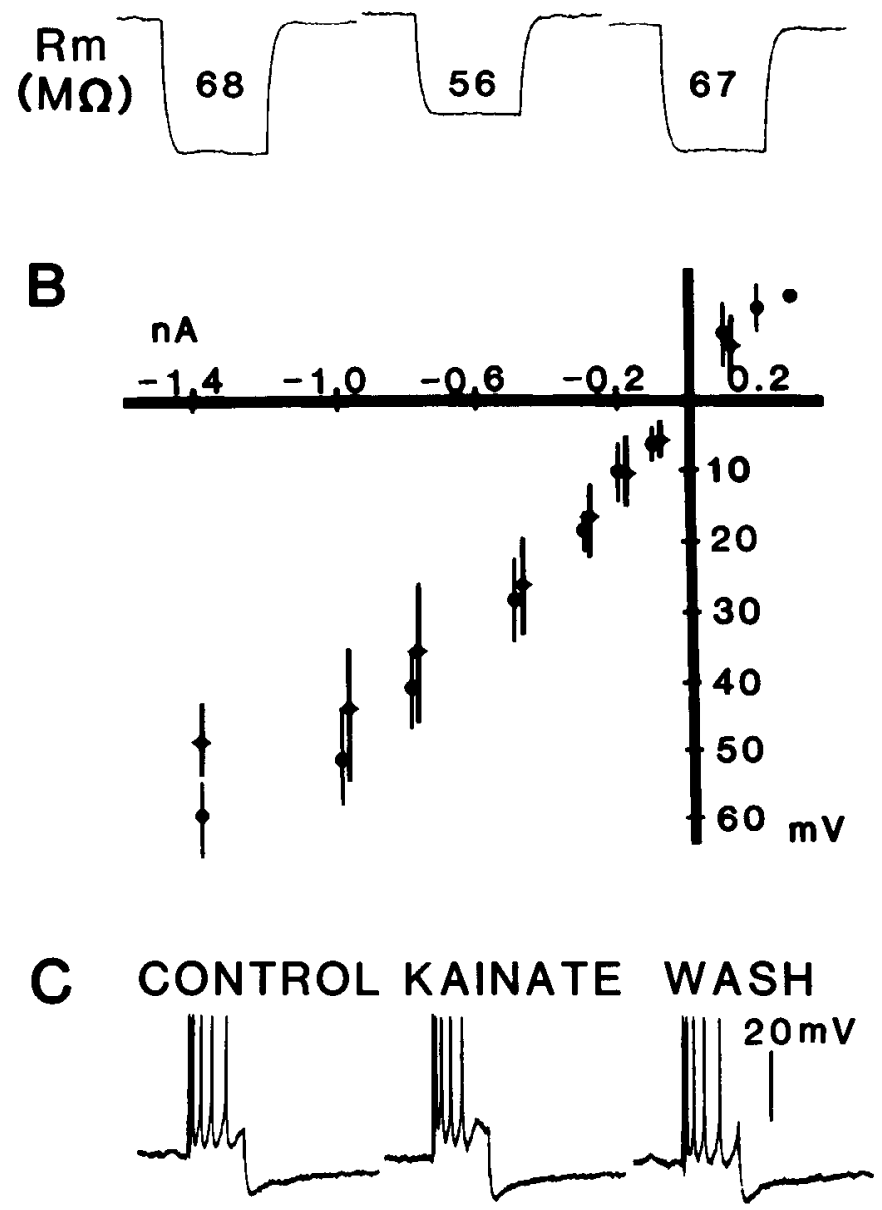

Figure 2. Effects of KA on membrane properties. $A$, Resting membrane potential $(E m)$ and input resistance $(\mathrm{Rm})$ for a cell during control, perfusion with $1 \mu \mathrm{M} \mathrm{KA}$, and wash periods. Traces in the lower row are voltage deflections in response to 100-msec, 0.5-nA hyperpolarizing constant-current pulses delivered through a balanced bridge circuit. $B$, Current versus voltage plotted for five cells during control ()) and $1 \mu \mathrm{M}$ KA ( ) periods. Vertical lines show standard deviations at each point. $C$, Afterhyperpolarizations, following trains of action potentials (in this example five action potentials) induced by direct current 50 -msec depolarizing pulses, are not significantly altered in the presence of $1 \mu \mathrm{M} \mathrm{KA}$.

for publication), measured at $150 \mathrm{msec}$ after delivery of an orthodromic stimulus to $\mathrm{s}$. radiatum, decreased reversibly to $40 \pm 23 \%$ of control values $(n=19)$, with a time course of decline similar to that for the IPSP. LHPs recovered to $80 \pm 20 \%$ of control values.

Effects of $K A$ in $C A 2 / 3$. Region CA2/3 is known to be a pacemaker for burst discharges in hippocampus (Schwartzkroin and Prince, 1978; Wong and Traub, 1983) and is more sensitive than CA1 to excitatory (DeMontigny and Tardif, 1981) and to neurotoxic (Nadler et al., 1978) effects of KA. Intracellular records were taken from six CA2/3 pyramidal cells to determine whether the effects of $\mathrm{KA}$ in that region were qualitatively different from those observed in CA1. One-half micromolar KA, a dose which did not significantly depolarize CA1 cells (cf. Robinson and Deadwyler, 1981), depolarized CA2/3 cells a mean of $7 \pm 4 \mathrm{mV}$.

Spontaneous bursting during the control period and bursts evoked during KA perfusion made it difficult to measure IPSPs in CA2/3. In three cells inhibitory potentials were not obscured by bursts, and in these cells IPSPs and LHPs declined markedly within 3 min of drug perfusion onset (Fig. 5, 1). This decline correlated with onset of spontaneous field potential bursting (Fig. 5, 2). Inhibitory potentials returned during the wash. Thus, we believe that CA2/3 cells are more sensitive to low doses of KA than are CA1 cells but that the effects on synaptic potentials in the two regions are similar. Subsequent analysis of IPSPs pertains to CA1.

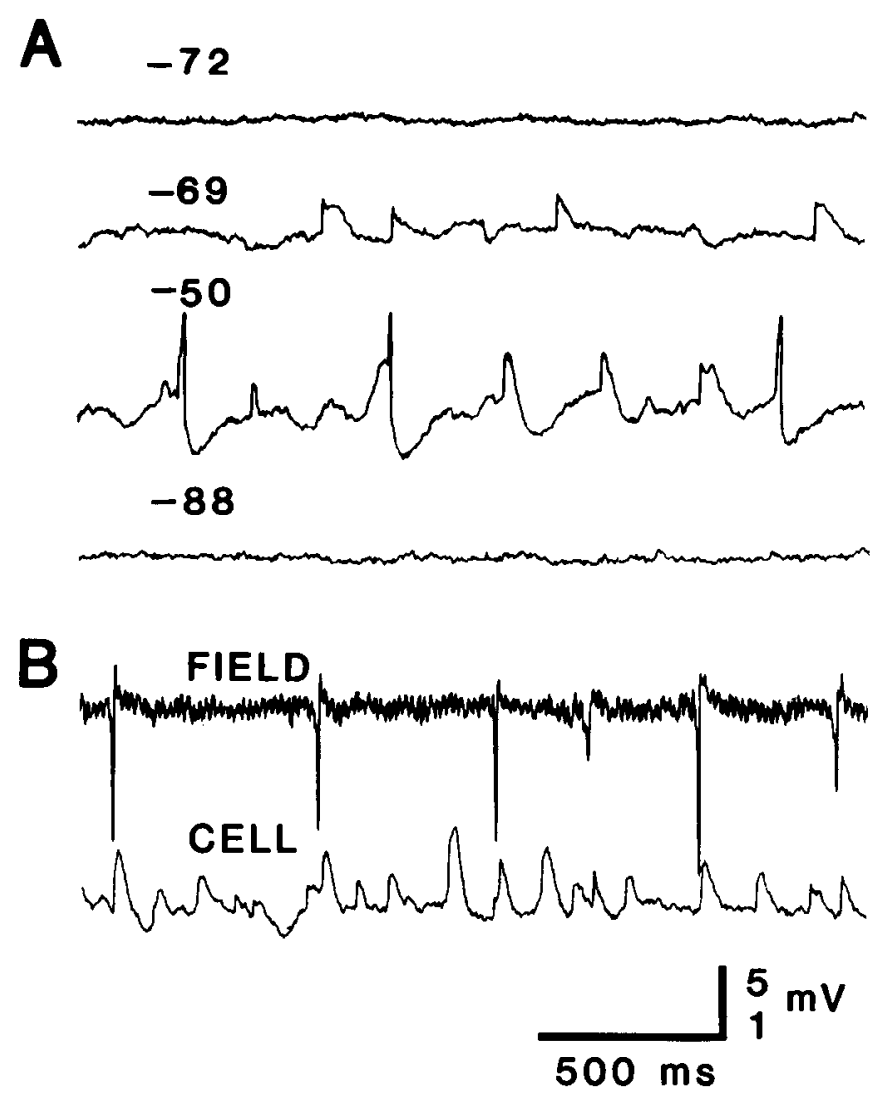

Figure 3. KA-induced voltage-sensitive membrane depolarizations ("bumps") in CA1 pyramidal neurons. $A$, Voltage sensitivity of depolarizations. The top trace shows the quiet intracellular base line recorded at the resting membrane potential of $-72 \mathrm{mV}$. The second trace was recorded $4 \mathrm{~min}$ after beginning perfusion with $0.5 \mu \mathrm{M} \mathrm{KA}$, at which time resting membrane potential had decreased by $3 \mathrm{mV}$. Spontaneous phasic depolarizations with quick rise and slow, variable fall phases are evident. Further depolarization of the membrane potential to $-50 \mathrm{mV}$ by $\mathrm{DC}$ injection intracellularly caused a striking increase in the amplitude of the bumps. In contrast, DC hyperpolarization of the membrane potential to $-88 \mathrm{mV}$ immediately and reversibly eliminated the bumps. $B$, Lack of clear correspondence between bumps and concurrently recorded field discharges. Voltage calibration is $5 \mathrm{mV}$ for the intracellular and $1 \mathrm{mV}$ for the extracellular records. 
A 1

CONTROL

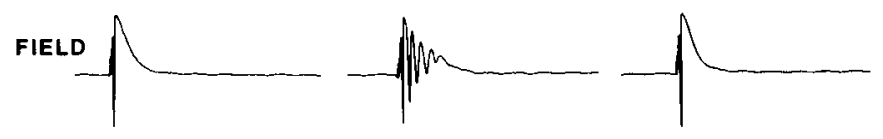

2

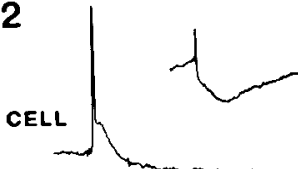

B
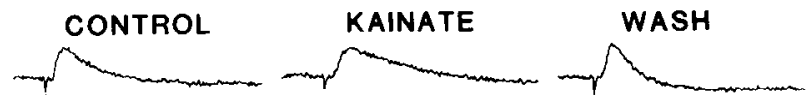

C 1

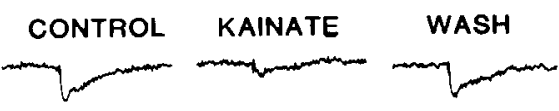

2

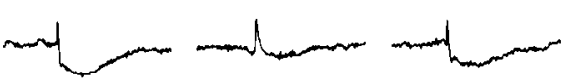

D

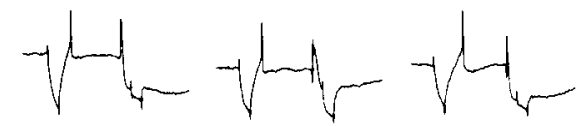

Figure 4. Effect of KA on synaptic potentials in CAl. A, Field $(A 1)$ and cell $(A 2)$ potentials in response to orthodromic stimulation during control, kainate perfusion, and wash periods. A paroxysmal depolarization shift-like event during drug perfusion is associated with repetitive firing of action potentials and field potentials. The inset in A2 shows the same cellular responses at slower sweep speed. Individual action potentials are not visible; however, loss of IPSP and LHP hyperpolarization is evident during exposure to KA. B, EPSPs elicited by orthodromic test stimuli to stratum radiatum with membrane potential polarized to approximately $-80 \mathrm{mV}$ to block action potentials or depolarization shifts. The EPSP amplitude is not affected by KA, but apparent EPSP duration increases reversibly, consistent with loss of later inhibitory phases. Note also a slowing in the EPSP rise time. $C$, Responses to antidromic stimuli $(C 1)$ and orthodromic stimuli to stratum radiatum $(C 2)$ are shown in a single cell before, during, and after perfusion with $1 \mu \mathrm{M} \mathrm{KA}$. In this cell synaptic potentials were not obscured by depolarization shifts, so reversible loss of the IPSPs and orthodromic LHP are clearly visible. $D$, KA $(1 \mu \mathrm{M})$ causes decrease of the input resistance shunt associated with IPSPs. During control, KA perfusion, and wash periods, pairs of 0.5$\mathrm{nA}, 50$-msec hyperpolarizing current pulses were injected into the cell, such that the second pulse arrived $50 \mathrm{msec}$ after an orthodromic stimulus. Input resistances (megohms) for the two pulses in control, KA perfusion, and wash periods, respectively, were 52 and $12(23 \%) ; 40$ and $28(70 \%)$; and 36 and $10(28 \%)$. Since the shunt due to the EPSP is largely over by $50 \mathrm{msec}$, the observed decrease in shunt in the presence of KA is best explained by a decrease in the IPSP. Sections $A$ to $D$ represent four different pyramidal cells. Voltage calibration is $10 \mathrm{mV}$ for the intracellular and $2 \mathrm{mV}$ for the extracellular records. Time calibrations are as indicated.

Mechanisms of IPSP decrease. The decline of pyramidal cell IPSPs after exposure to KA could, in principle, be a result of several factors: (1) input resistance changes, (2) "masking" by concurrent excitatory potentials, (3) a shift in the equilibrium potential for the
IPSP, (4) decreased transmitter release from presynaptic terminals, (5) alterations of GABA uptake, or (6) postsynaptic interactions among KA, GABA, and GABA receptors.

The first possibility is untenable on quantitative grounds since the IPSP decrease was on the order of $75 \%$ and the input resistance decrease was $15 \%$. The possibility of IPSP masking during KA perfusion was effectively ruled out by showing that the normal shunting of input resistance by the IPSP was attenuated reversibly in the presence of KA (Fig. $4 D$ ). Direct measurement of the IPSP reversal potential in KA was difficult because of large bursts obscuring the diminishing IPSPs. However, IPSP equilibrium potentials were plotted in two cells at a time when IPSPs were reduced about 50\%; the magnitude of the shift was small. Furthermore, such a mechanism would have preserved the membrane resistance shunt (Dingledine and Langmoen, 1980). Depolarizing IPSPs recorded by means of $\mathrm{KCl}$-filled intracellular pipettes also disappeared in KA (Fig. 6A3), an unlikely event if the mechanism of IPSP decreases were a shift

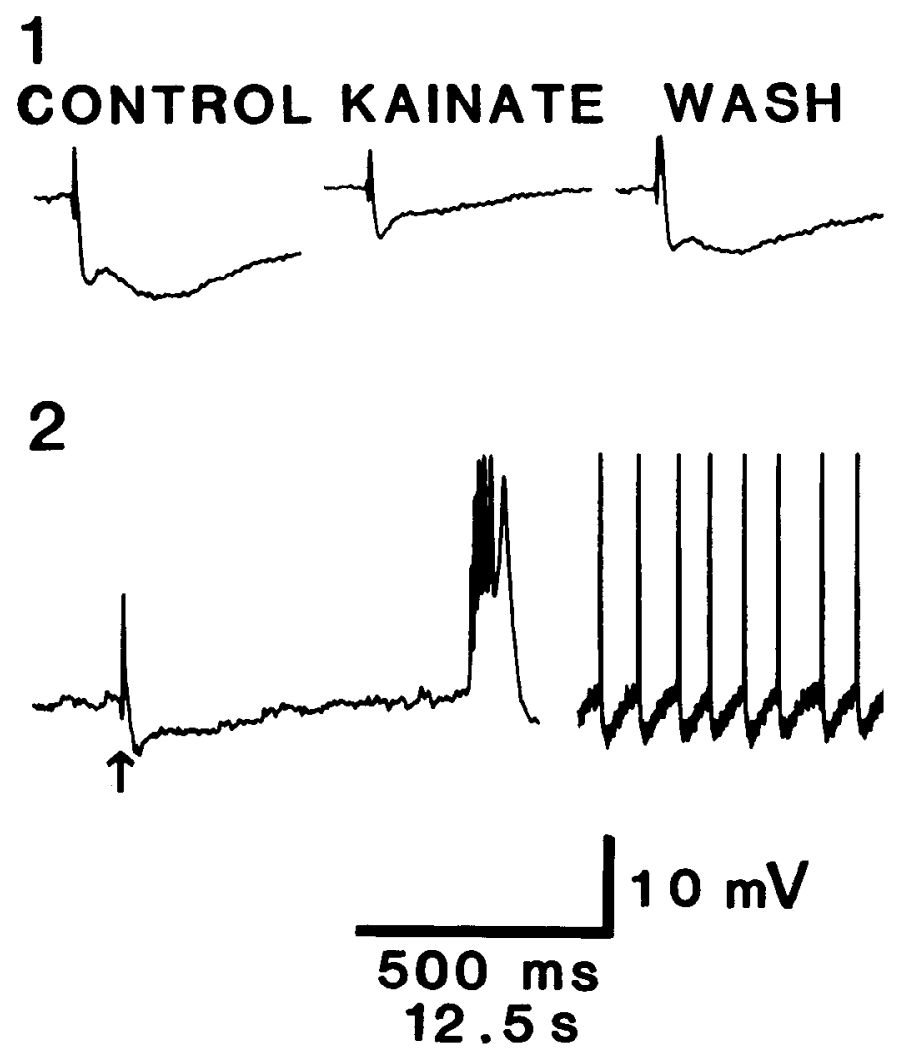

Figure 5. Effects of KA on a neuron in CA2/3. In a CA2/3 cell, $0.5 \mu \mathrm{M} \mathrm{KA}$ caused reversible declines of the IPSP and the LHP. Synaptic potentials in 1 were triggered by stimuli to mossy fibers in stratum radiatum of CA4. Records in 2 were taken at a time corresponding to the middle trace of 1,3 min after the start of drug perfusion. The first discharge in the lower left-hand trace was triggered orthodromically; the second was spontaneous. The lower right-hand trace shows a slower sweep speed recording of rhythmical spontaneous cell bursting after exposure to KA. Individual action potentials are not resolvable at this speed. Voltage calibration is $10 \mathrm{mV}$ in all cases. The time calibration is $12.5 \mathrm{sec}$ for the right-hand trace in 2 and $500 \mathrm{msec}$ elsewhere. 
in the IPSP equilibrium potential. We could not address directly the issue of possible alterations in transmitter uptake caused by KA, but since the time course and morphology of evoked IPSPs remained fairly constant as the amplitude declined, such a mechanism was also unlikely.

Presynaptic effects of KA on inhibitory pathways were explored by studying spontaneous IPSPs in pyramidal cells. Spontaneous IPSPs were reversed with $3 \mathrm{M} \mathrm{KCl-}$ filled recording pipettes which increased intracellular chloride concentration and shifted the driving force for IPSPs in the depolarizing direction. The frequency and amplitude of these TTX-sensitive spontaneous IPSPs can be utilized as an indirect measure of activity in inhibitory interneurons (Alger and Nicoll, 1980b).

Figure 6 portrays the sequence of effects of KA on spontaneous IPSPs. Within 5 min of starting perfusion, the amplitude and rate of occurrence of spontaneous IPSPs increased markedly, shown at slow sweep speed in Figure $6 A 1$ and at fast speed in Figure 6A2. Subsequently, the frequency and amplitude of spontaneous IPSPs declined and remained low (Fig. 6A2, third row) until KA was washed off. During the wash period (fourth row), there was a transient increase of spontaneous IPSP frequency and amplitude and then a return approximately to control levels ( fifth row). Amplitudes of evoked IPSPs (Fig. 6A3, stimuli delivered at time marked with arrow) paralleled those of spontaneous IPSPs.

Picrotoxin (Fig. 6B) and TTX (Fig. 6C) each eliminated the reversed depolarizing potentials, which supports their identification as spontaneous IPSPs, resulting from activity in the interneurons. Figure $6 D$ charts the average spontaneous IPSP incidence per minute for nine CA1 cells in the control period $(A)$, early in the period of KA perfusion $(B)$, later in KA perfusion $(C)$, and early $(D)$ and late $(E)$ in the wash period. The usual time period of epileptiform field activity is marked with a bar. The data suggest that KA initially increases but

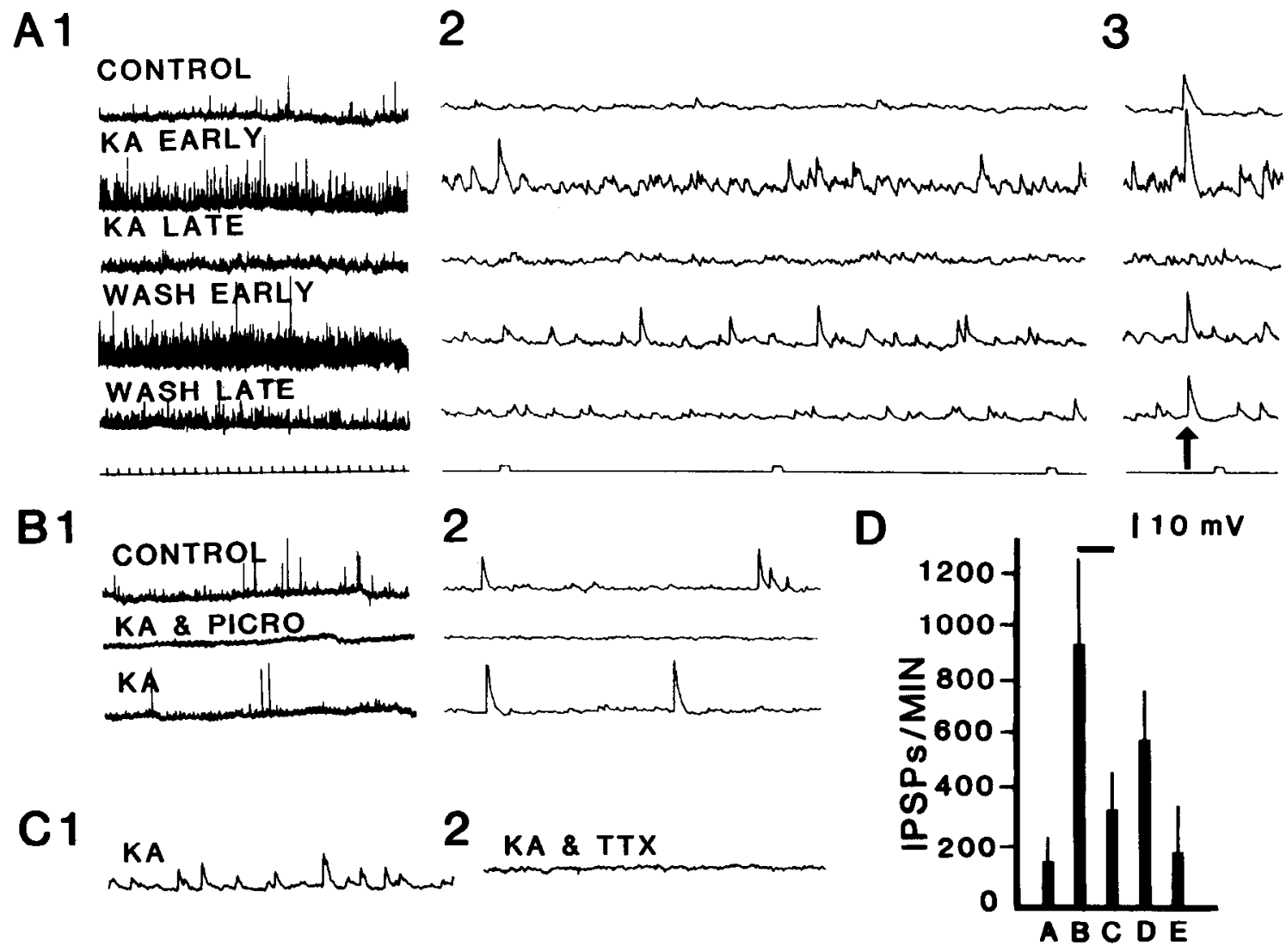

Figure 6. Effect of KA on spontaneous IPSPs. A, Spontaneous IPSPs at different times before and after exposure to $5 \mu \mathrm{M}$ KA. $A 1$ shows the potentials at a slow sweep speed and $A 2$ at a fast sweep speed. $A 3$ depicts a response to an orthodromic stimulus delivered at the time indicated by the vertical arrow. The top arrow shows control levels of spontaneous and evoked IPSPs. KClfilled electrodes were used to record and the IPSPs are inverted to depolarizing potentials. The second rou was recorded 3 min after the start of KA perfusion, the third row $10 \mathrm{~min}$ after, the fourth row $2 \mathrm{~min}$ after starting the wash, and the fifth row 15 min later. One-second timer marks are indicated in the lowest trace of $A$. $B$, Spontaneous IPSPs are present in the control period, absent after $15 \mathrm{~min}$ of perfusion with $1 \mu \mathrm{M} \mathrm{KA}$ and $60 \mu \mathrm{M}$ picrotoxin, and return when the solution is switched to $\mathrm{KA}$ alone. $C$, The lower left trace (C1) shows spontaneous IPSPs in KA. After addition of $1 \mu \mathrm{M}$ TTX to $1 \mu \mathrm{M}$ KA, spontaneous IPSPs rapidly disappear (C2). The timer marks in $A 1$ apply to $B 1$; the marks in $A 2$ apply to $B 2$ and $C$. The voltage calibration is shown beneath $A 3$ and applies to all traces. $D$, A plot of frequency of spontaneous IPSPs per minute (Means and SDs shown) in nine cells studied: $(A)$ during control periods; $(B) 3$ to 5 min after starting KA; $(C) 10$ min after starting KA; $(D) 5$ to 7 min after starting the wash; and $(E)$ after at least $45 \mathrm{~min}$ in the wash. Lellers on the abscissa correspond to these times. IPSPs were counted for 10 $\mathrm{sec}$ real time and extrapolated to $1 \mathrm{~min}$. Only potentials with the morphology of inverted IPSPs and at least $1 \mathrm{mV}$ in amplitude were counted. $A, B$, and $C$ represent three different cells. 

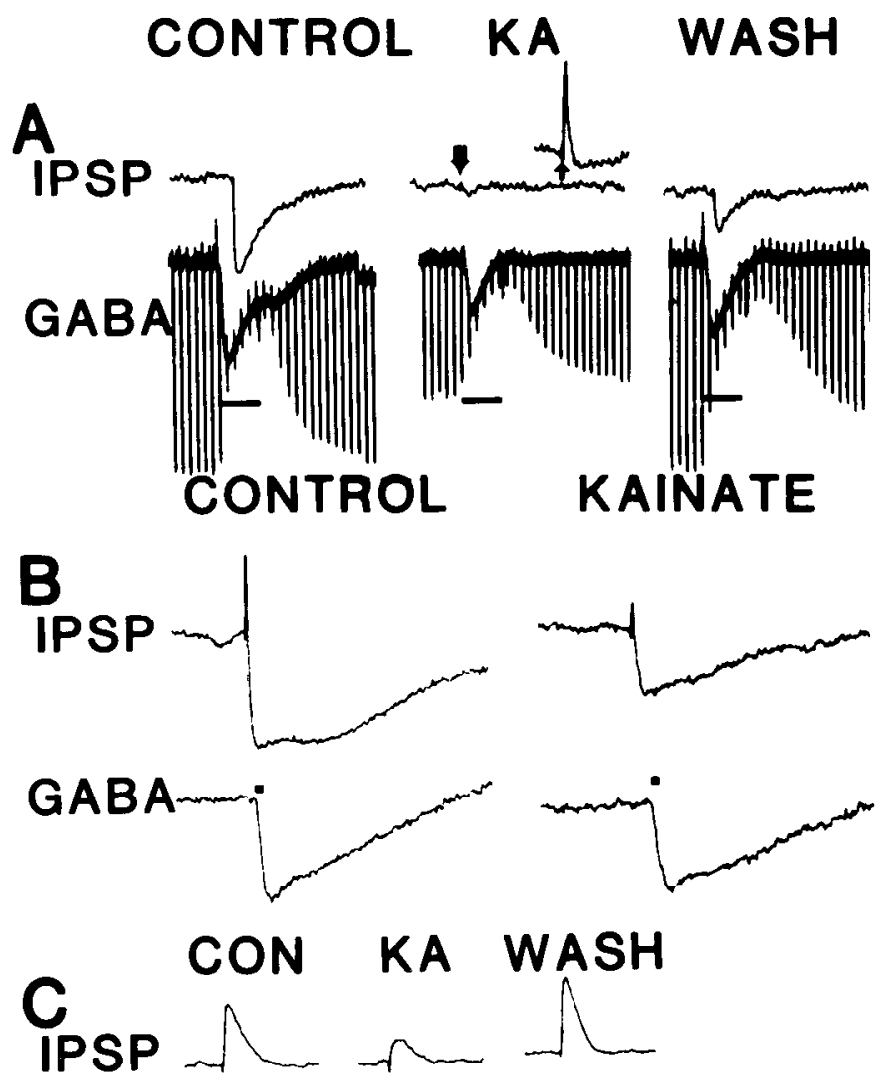
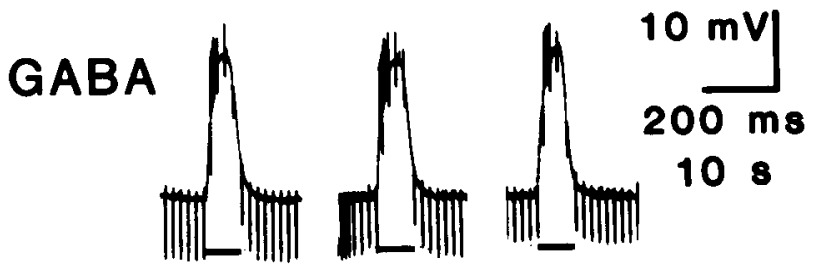

Figure 7. Effect of KA on locally applied GABA. $A$, IPSPs and responses to iontophoresis of GABA with 100-nA, 5-sec currents. During the control period (left traces) a $60-\mathrm{V}$ antidromic stimulus induced a robust IPSP. GABA iontophoresis caused a similar hyperpolarization (note different time scale) and a marked input resistance shunt. Three minutes after starting perfusion with $5 \mu \mathrm{M}$ KA (middle trace), the same antidromic stimulus (arrow) failed to produce a response. Increasing the stimulus to $100 \mathrm{~V}$ did not produce an IPSP (inset). In contrast, the hyperpolarization caused by direct application of $\mathrm{G} \Lambda \mathrm{B} \Lambda$ was reduced only by an amount consistent with the decreased input resistance in KA (i.e., 36\%). The effects partially reversed in the wash (right column). The initial resting potential of the cell was $-64 \mathrm{mV}$, and all traces were taken at this level. However, in $5 \mu \mathrm{M}$ KA the unaltered RMP was $-49 \mathrm{mV}$. $B$, Response to GABA applied by pressure ejection with a 20 -msec, 10 psi pulse (bottom trace) can be compared to the response to an orthodromic test stimulus (top trace, same time scales). KA produced a greater effect upon the IPSP response than upon the GABA response. All records were taken with the membrane slightly depolarized with DC injection to emphasize the IPSP. C, Antidromic IPSPs and GABA responses were inverted by $\mathrm{KCl}$-filled intracellular pipettes. GABA was applied by iontophoresis using 20-nA, 3-sec currents. The resting potential in control and $1 \mu \mathrm{M} \mathrm{KA}$ perfusion periods was about $-65 \mathrm{mV}$. All recordings were taken with the membrane hyperpolarized to $-80 \mathrm{mV}$. Constant $0.2-\mathrm{nA}$ hyperpolarizing current pulses were delivered during the iontophor- then depresses activity of the inhibitory GABAergic interneurons.

One means by which KA might exert some of its effects would be by elevation of $\left[\mathrm{K}^{+}\right]_{0}$. Therefore, we measured $\left[\mathrm{K}^{\prime}\right]_{0}$ levels during control, drug perfusion, and wash periods in 12 slices from 3 rats, using ion-sensitive microelectrodes, and in 2 slices using intracellular recordings from putative glial cells.

Perfusion with $1 \mu \mathrm{M} \mathrm{KA}$ for 15 min caused an average increase of only $0.6 \pm 0.3 \mathrm{mM}(n=10)$ from the base line of $5.4 \mathrm{mM}$. Similarly, $10 \mu \mathrm{M} \mathrm{KA}$ induced an increase of only $2.7 \pm 1.4 \mathrm{mM}(n=4)$. The mean increase $\left[\mathrm{K}^{+}\right]_{0}$ associated with repetitive field potential discharges was $0.6 \pm 0.2 \mathrm{~mm}(n=5)$. Depression of field potentials by KA to $50 \%$ or more of control amplitudes occurred at an average $\left[\mathrm{K}^{+}\right]_{0}$ increase of $0.8 \pm 0.7 \mathrm{mM}$. Field potentials in these same slices were not depressed when $\left[\mathrm{K}^{+}\right]_{0}$ levels were elevated nearly $3.0 \mathrm{~mm}$ by orthodromic tetani. In three of the four slices exposed to $10 \mu \mathrm{M} \mathrm{KA},\left[\mathrm{K}^{+}\right]_{0}$ undershot by approximately $0.5 \mathrm{mM}$ early in the wash period and then returned to control levels. Two putative glial cells depolarized $3 \mathrm{mV}$ each at the time of repetitive field bursting, corresponding to a $\left[\mathrm{K}^{+}\right]_{0}$ elevation of about $0.9 \mathrm{~mm}$ (Alger et al., 1983). Temporal correlations between field potential depression and increases or decreases of $\left[\mathrm{K}^{+}\right]_{0}$ were poor.

Therefore, data from ion-sensitive potassium electrodes and from glial cell recordings portray rather modest increases of $\left[\mathrm{K}^{+}\right]_{0}$ during periods of field epileptiform activity and field potential depression.

The decrease of IPSP amplitude could result from postsynaptic effects of KA. To evaluate this possibility, we studied the effects of bath perfusion of $1 \mu \mathrm{M} \mathrm{KA}$ upon the pyramidal cell response to locally applied GABA. GABA was applied iontophoretically to nine cells and by pressure ejection to two cells. Although responses to pressure ejection were much faster than responses to iontophoresis (Fig. 7, $A$ and $B$; note different time scales), results from the two methods were otherwise comparable. Thus, each method served as a control for possible artifacts of the other.

Six of the nine cells exposed to iontophoretically applied GABA were studied with $\mathrm{KCH}_{3} \mathrm{SO}_{4}$ pipettes; of the six, we focused attention on four that exhibited at least partial reversal of KA effects upon washout. For these four cells and the two cells studied by pressure ejection of GABA, the amplitude of the hyperpolarizing response to GABA in the presence of KA was calculated as a percentage of the control amplitude, and the percentages were corrected for the measured concurrent changes in input resistance. There was no statistically significant effect of KA on GABA responses, although results were variable and depression of the hyperpolarizing GABA response occurred in some experiments.

Hyperpolarizing responses to GABA are probably mixed potentials with both depolarizing and hyperpolarizing components (Alger and Nicoll, 1979; Andersen et

etic recordings. Although $\mathrm{KA}$ reversibly attenuated the evoked IPSP, the response to GABA remained unaffected. In $A, B$, and $C$ the period of active GABA application is denoted by a horizontal bar. 
al., 1980), and this overlap of effects may complicate interpretation of $\mathrm{KA}$ effects on the overall response to GABA. Therefore, in three cells GABA responses were made wholly depolarizing by elevating intracellular chloride concentration. A clear dissociation between loss of the (inverted) IPSP and response to GABA was evident (Fig. $7 C$ ).

These results do not entirely rule out the possibility of a postsynaptic interaction between KA and GABA; however, they do demonstrate that a change in postsynaptic responsiveness to GABA is not the major factor in loss of inhibition caused by KA.

Depressive effects of $K A$. As noted by others (Koerner and Cotman, 1982; Collingridge et al., 1983; Westbrook and Lothman, 1983), KA in concentrations above $5 \mu \mathrm{M}$, or during prolonged perfusion at $1 \mu \mathrm{M}$, can lead to depression of spontaneous and evoked field activity in CA1. Overdepolarization of pyramidal cells has been proposed as a possible mechanism for this depression (Shinozaki and Konishi, 1970). In our experiments, KA produced only small membrane depolarizations; consequently, we hypothesized that field depression resulted primarily from a failure of synaptic transmission. Figure $8 A$ depicts simultaneous field potential records from $\mathrm{s}$. radiatum in the region of afferent excitatory synapses (Andersen et al., 1966) and from s. pyramidale. The broad negative extracellular EPSP remained robust $4 \mathrm{~min}$ after KA application (Fig. 8A2, lop row), but at 7 min both extracellular EPSP and population spike declined. The prefiber volley (open diamonds in Fig. $8 A$ ), which reflects afferent fiber discharge of the Schaffer collateral-commissural system (Langmoen and Andersen, 1981), was relatively preserved, as was the antidromically evoked population discharge (not shown). The potential recovered with washing (Fig. 8A4).

Figure $8 B$ illustrates intracellular data from a cell in which the resting membrane potential depolarized only about $5 \mathrm{mV}$ during perfusion with $\mathrm{KA}$ and input resistance remained nearly constant; yet, the cell exhibited a marked depression of EPSPs. The first column of Figure $8 B$ shows antidromically and orthodromically evoked field activity concurrently with the intracellular record. Column 2 was recorded 6 min after starting $1 \mu \mathrm{M}$ perfusion of KA. The test shock to s. radiatum elicited multiple field and cell discharges. The adjacent column (Fig. $8 B 3$ ) was recorded after $23 \mathrm{~min}$ of perfusion; both field potential discharges and cell responses were markedly reduced. At that time antidromic stimulation (Fig. 8B6) and intracellularly injected depolarizing current pulses (Fig 8B7) could still fire the cell, demonstrating that the failure was synaptic or presynaptic. The relative preservation of the antidromically elicited field population spike implies that the majority of pyramidal neurons maintained membrane polarization sufficient to generate action potentials. The two right columns (Fig. 8, B4 and $B 5)$ show recovery in the wash stage. Excitatory potentials recovered before inhibitory potentials; during this lag the cells burst. Thereafter, inhibitory potentials recovered, and cell and field responses returned to control levels.

The above pattern of generalized depression of syn-

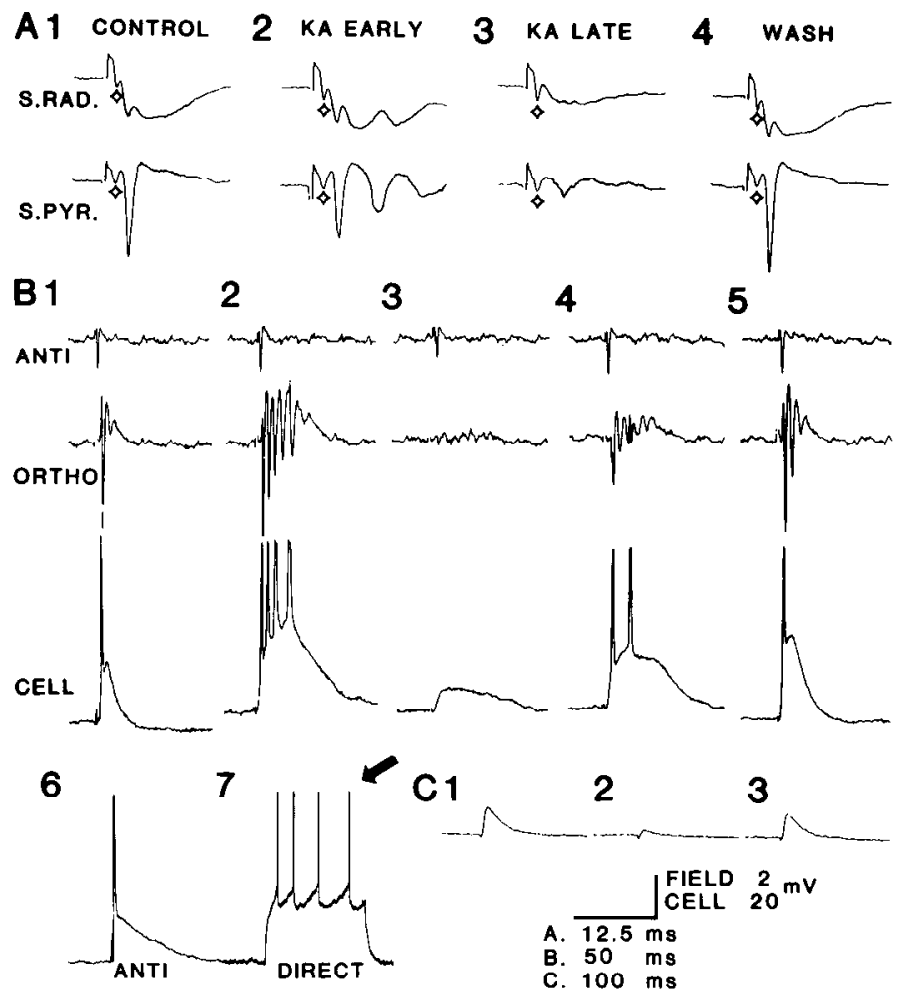

Figure 8. Depressant effects of KA. A, Simultaneous field potential recordings from the region of the excitatory synapses (S.RAD.) and the pyramidal cell body layer (S.PYR.). During the control period, an orthodromic stimulus evoked a single population spike in stratum pyramidale and a negative extracellular EPSP field potential in stratum radiatum. Early in 5 $\mu \mathrm{M}$ KA (second column), multiple population spikes appeared, but the extracellular EPSP remained unchanged. Later, both EPSPs and population spikes declined, although the afferent fiber volley $(\diamond)$ was intact. The effects reversed with washing. $B$, Simultaneous records of field and cell potentials are displayed at different times in relation to perfusion with $1 \mu \mathrm{M}$ KA. The orthodromically evoked field and cell responses were recorded simultaneously; antidromically elicited field responses were taken no more than $5 \mathrm{sec}$ after the other corresponding potentials. $B 1$ shows the control response. $B 2$ was recorded 6 min after starting $1 \mu \mathrm{M} \mathrm{KA}$, when epileptiform activity was present. $B 3$ was recorded $23 \mathrm{~min}$ after onset of KA perfusion. Depression of the orthodromic field response and the intracellular response was marked. At this time the cell could be fired by antidromic stimuli $(B 6)$ or direct depolarizing $0.5-\mathrm{nA}, 100$ msec current injections $(B 7) . B 1$ was taken 11 min after start of wash and $B 553 \mathrm{~min}$ into the wash. The resting membrane potential of this cell was about $-75 \mathrm{mV}$. No DC polarization was given; therefore the cell trace depicts the actual membrane potential levels. $C$, In another cell the loss of the orthodromically evoked EPSP after $15 \mathrm{~min}$ of exposure to $1 \mu \mathrm{M} \mathrm{KA}$ is shown. This cell was hyperpolarized with DC during the stimuli to prevent occurrence of action potentials or bursts.

aptic activity, relatively independent of resting membrane potential, was observed to be quite widespread. Figure $8 C$ was taken from another cell in which the EPSP was depressed by exposure to KA. In this cell the membrane potential was artificially polarized to $-80 \mathrm{mV}$ to eliminate IPSPs and voltage-dependent regenerative 
membrane conductances, thereby rendering the reversible depression of the EPSP more visible.

In summary, KA depresses synaptic activity, having a greater initial effect on inhibitory activity, but at high doses or prolonged perfusion times with moderate doses, a depression of EPSPs is also demonstrable. This latter effect does not require significant depolarization of pyramidal cell somata.

\section{Discussion}

The present experiments clarify the mechanisms by which KA produces spontaneous and triggered epileptiform burst potentials in the hippocampus (Ryan and Cotman, 1978; Schwarcz et al., 1978; Menini et al., 1980; Ben-Ari et al., 1981; Lothman et al., 1981; Zaczek et al., 1981; Collingridge et al., 1983; Westbrook and Lothman, 1983). The action of KA is dose- and time-dependent. One micromolar $\mathrm{KA}$ produces epileptiform bursting within $15 \mathrm{~min}$ in CA1. At this time the drug has minimal effects on passive membrane properties (cf. Robinson and Deadwyler, 1981; Westbrook and Lothman, 1983), action potentials, calcium-mediated afterhyperpolarizations, fiber conduction, and EPSPs.

Based on our data, the principal action of KA appears to be synaptic depression, with influence first on inhibitory potentials (the IPSP and the LHP) and soon thereafter on the EPSP. During the time when inhibition is blunted with respect to excitation cells and field potentials burst repetitively. Thus, our results indicate that the excitatory phenomena which do occur at this stage (Collingridge et al., 1983; Westbrook and Lothman, 1983) may be secondary to decreased inhibition, as inferred by Sloviter and Damiano (1981) on the basis of field potential studies. While depolarization block has frequently been proposed as a mechanism by which KA may cause depression of neuronal activity, our data do not support this hypothesis for the relatively low doses of $\mathrm{KA}$ we used, at least for the CA1 region. Depression of CA1 excitability was correlated with only modest cellular depolarizations. We cannot rule out depolarization block of CA2/3 cells, their terminals, or those of other afferent systems as a cause of depression of synaptic transmission.

Our observations suggest that KA exerts a preferential effect at early stages upon hippocampal inhibitory interneuronal circuitry (Andersen et al., 1964). Studies of neurotransmitters have shown that microinjection of KA into in vivo hippocampus induces a major decline in biochemical markers for GABAergic transmission (Fonnum and Walaas, 1978; Schwarcz et al., 1978; Schmid et al., 1980; Heggli and Malthe-Sorenssen, 1982). Since GABA markers are believed to be associated primarily with inhibitory interneurons in hippocampus (Ribak et al., 1978), our findings of a potent physiological effect of $\mathrm{KA}$ upon interneurons may relate to the subsequent toxic effect upon GABAergic interneurons.

The means by which KA decreases synaptic potentials is not entirely clear. Part of the effect can be attributed to minor decreases in input resistance, alterations in extracellular potassium concentration, shifts of ionic equilibrium potentials, and possibly postsynaptic interactions between KA and endogenous neurotransmitters. In our experiments, these factors were not quantitatively adequate to account for the marked diminution in pyramidal cell IPSPs; furthermore, in individual cells none of these factors correlated reliably with the concurrent loss of the IPSP and later of the EPSP. Consequently, we infer that the main influence of KA on hippocampal synaptic potentials is exerted presynaptically. Our data do not specify whether the presynaptic effect occurs at the inhibitory terminals synapsing onto pyramidal cells (Andersen et al., 1964), at the cell bodies of the inhibitory interneurons, or at the systems afferent to the interneurons, including presumed glutamatergic recurrent collaterals of pyramidal cell axons (Storm-Mathisen, 1977). This point would be clarified by simultaneous intracellular recordings from pyramidal cells and inhibitory interneurons.

A direct measure of $\mathrm{KA}$ action upon transmitter release has been obtained at the locust neuromuscular junction (Daoud and Usherwood, 1975), where KA increases quantal release at low dosages and suppresses release at high dosages. Our data showing a transient increase in inhibition, followed by a decrease, are consistent with the above effects. One possible mechanism for this sequence would be a depolarization of the presynaptic terminals, leading initially to greater transmitter release, followed by decreased release as a result of depletion or terminal depolarization block. The fact that a subsequent increase in transmitter release was seen on washout may argue for a dose rather than true time dependency of these transitions. Nevertheless, our data do not directly address this issue.

If KA has presynaptic effects in hippocampus, the question arises: are there presynaptic receptors for KA? Autoradiographic evidence for KA receptors on mossy fiber terminals has been equivocal (Monaghan and Cotman, 1982). Recently, however, Ferkany et al. (1982) have shown that glutamate release from axon terminals in hippocampus is markedly increased by perfusion with $\mathrm{KA}$. Although their study did not note a change in GABA release during perfusion with $\mathrm{KA}$, the base line GABA release was not measurable.

A large body of literature pertains to the neurotoxic actions of KA (Nadler, 1979; Coyle et al., 1981). The present experiments were designed to study KA epileptogenic effects, and at concentrations where at least partial reversal of drug effect was possible. Therefore, the issue of neurotoxicity was not addressed directly. We would speculate that the unusual voltage-dependent paroxysmal depolarizations ("bumps") observed in several cells soon after exposure to KA reflect large influxes of cations into neurons (MacDonald and Porietis, 1982) and that this contributes to the injurious effects of KA. Because the bumps appeared briefly and then faded and because they were not present in all cells, we were unable to study them systematically.

KA convulsant action is clearly different from those of penicillin, bicuculline, and picrotoxin-all of which are in large part postsynaptic GABA antagonists (Alger, 1984). Nevertheless, a common feature to all of the above 
epileptogenic compounds, including $\mathrm{KA}$, is the capacity to decrease inhibition.

\section{References}

Alger, B. E. (1984) Hippocampus: Electrophysiological studies of epileptiform activity in vitro. In Brain Slices, R. Dingledine, ed., pp. 155-199, Plenum Press, New York.

Alger, B. E., and R. A. Nicoll (1979) GABA-mediated biphasic inhibitory responses in hippocampus. Nature 281: 315-317.

Alger, B. E., and R. A. Nicoll (1980a) Epileptiform burst afterhyperpolarization: Calcium-dependent potassium potential in hippocampal CA1 pyramidal cells. Science 210: 1122-1124.

Alger, B. E., and R. A. Nicoll (1980b) Spontaneous inhibitory post-synaptic potentials in hippocampus: Mechanism for tonic inhibition. Brain Res. 200: 195-200.

Alger, B. E., and R. A. Nicoll (1982) Pharmacological evidence for two kinds of GABA receptor on rat hippocampal pyramidal cells studied in vitro. J. Physiol. (Lond.) 328: 367-390.

Alger, B. E., M. McCarren, and R. S. Fisher (1983) On the possibility of simultaneously recording from two cells with a single microelectrode in the hippocampal slice. Brain Res. 270: 137-141.

Andersen, P., J. C. Eccles, and Y. Loyning (1964) Location of postsynaptic inhibitory synapses on hippocampal pyramids. J. Neurophysiol. 27: 592-607.

Andersen, P., T. W. Blackstad, and T. Lomo (1966) Location and identification of excitatory synapses on hippocampal cells. Exp. Brain Res. 1: 236-248.

Andersen, P., R. Dingledine, L. Gjerstad, L. Langmoen, and I. A. Mosfeldt-Laursen (1980) Two different responses of hippocampal pyramidal cells to application of gamma-aminobutyric acid. J. Physiol. (Lond.) 305: 279-296.

Ault, B., R. H., Evans, A. A. Francis, D. J. Oakes, and J. C. Watkins (1980) Selective depression of excitatory amino acid induced depolarizations by magnesium ions in isolated spinal cord preparations. J. Physiol. (Lond.) 307: 413-428.

Ben-Ari, Y., E. Tremblay, D. Riche, G. Ghilini, and R. Naquet (1981) Electrographic, clinical and pathological alterations following systemic administration of kainic acid, bicuculine or pentylenetetrazole: Metabolic mapping using the deoxyglucose method with special reference to the pathology of epilepsy. Neuroscience 6: 1361-1391.

Biscoe, T. J., R. H. Evans, P. M. Headley, M. R. Martin, and J. C. Watkins (1976) Structure-activity relations of excitatory amino acids on frog and rat spinal neurones. Br. J. Pharmacol. 58: 373-382.

Collingridge, G. L., S. J. Kehl, R. Loo, and H. McLennan (1983) Effects of kainic and other amino acids on synaptic excitation in rat hippocampal slices. I. Extracellular analysis. Exp. Brain Res. 52: 170-178.

Constanti, A., and A. Nistri (1976) A comparative study of the effects of glutamate and kainate on the lobster muscle fibre and the frog spinal cord. Br. J. Pharmacol. 57: 359-368.

Coyle, J. T., S. J. Bird, R. H. Evans, R. L. Gulley, J. V. Nadler, W. J. Nicklas, and J. W. Olney (1981) Excitatory amino acid neurotoxins: Selectivity, specificity, and mechanism of action. Neurosci. Res. Program Bull. 19: 337-427.

Daoud, A., and P. N. R. Usherwood (1975) Action of kainic acid on a glutamatergic synapse. Comp. Biochem. Physiol. $52 C: 51-53$.

De Montigny, C., and D. Tardif (1981) Differential excitatory effects of kainic acid on CA3 and CA1 hippocampal pyramidal neurons: Further evidence for the excitotoxic hypothesis and for a receptor-mediated action. Life Sci. 29: 2103-2111.

Dingledine, R., and L. Gjerstad (1980) Reduced inhibition during epileptiform activity in the in vitro hippocampal slice. J. Physiol. (Lond.) 305: 297-313.

Dingledine, R., and I. A. Langmoen (1980) Conductance changes and inhibitory actions of hippocampal recurrent IPSPs. Brain Res. 185: 277-287.

Engberg, I., J. A. Flatman, and J. D. C. Lambert (1978) The action of N-methyl-D-aspartic and kainic acids on motoneurones with emphasis on conductance changes. Br. J. Pharmacol. 64: 384P.

Evans, R. H. (1980) Evidence supporting the indirect depolarization of primary afferent terminals in the frog by excitatory amino acids. J. Physiol. (Lond.) 298: 25-35.

Evans, R. H., A. A. Francis, and J. C. Watkins (1977) Effects of monovalent cations on the responses of motoneurones to different groups of amino acid excitatants in frog and rat spinal cord. Experientia 3: 246-248.

Ferkany, J. W., R. Zaczek, and J. T. Coyle (1982) Kainic acid stimulates excitatory amino acid neurotransmitter release at presynaptic receptors. Nature 298: 757-759.

Fonnum, F., and I. Walaas (1978) The effect of intrahippocampal kainic acid injections and surgical lesions on neurotransmitters in hippocampus and septum. J. Neurochem. 31:11731181.

Hall, J. G., T. P. Hicks, H. McLennan, T. L. Richardson, and H. V. Wheal (1979) The excitation of mammalian central neurones by amino acids. J. Physiol. (Lond.) 286: 29-39.

Heggli, D. E., and D. Malthe-Sorenssen (1982) Systemic injection of kainic acid: Effect on neurotransmitter markers in piriform cortex, amygdaloid complex and hippocampus and protection by cortical lesioning and anticonvulsants. Neuroscience $7:$ 1257-1264.

Hotson, J. R., and D. A. Prince (1980) A calcium-activated hyperpolarization follows repetitive firing in hippocampal neurons. J. Neurophysiol. 43: 409-419.

Johnston, G. A. R., D. R. Curtis, J. Davies and R. M. McCulloch (1974) Spinal interneurone excitation by conformationally restricted analogues of L-glutamic acid. Nature 248: 804-805.

Kandel, E. R., and W. A. Spencer (1961) Excitation and inhibition of single pyramidal cells during hippocampal seizure. Exp. Neurol. 4: 162-179.

Kizer, J. S., C. B. Nemeroff, and W. W. Youngblood (1978) Neurotoxic amino acids and structurally related analogs. Pharmacol. Rev. 29: 301-318.

Koerner, J. F., and C. W. Cotman (1982) Response of Schaffer collateral-CA1 pyramidal cell synapses of the hippocampus to analogues of acidic amino acids. Brain Res. 251: 105-115.

Langmoen, I. A., and P. Andersen (1981) The hippocampal slice in vitro. A description of the technique and some examples of the opportunities it offers. In Electrophysiology of Isolated Mammalian CNS Preparations, G. A. Kerkut and H. V. Wheal, eds., pp. 52-105, Academic Press, Inc., New York. Lothman, E. W., R. C. Collins, and J. A. Ferrendelli (1981) Kainic acid-induced limbic seizures: Electrophysiological studies. Neurology 31: 806-812.

MacDonald, J. F., and A. V. Porietis (1982) Two conductances activated by excitatory amino acids. Soc. Neurosci. Abstr. 8 : 796.

McGeer, E. G., J. W. Olney, and P. L. McGeer (1978) Kainic Acid as a Tool in Neurobiology, Raven Press, New York.

Menini, C., B. S. Meldrum, D. Riche, C. Silva-Comte, and J. M. Stutzmann (1980) Sustained limbic seizures induced by intraamygdaloid kainic acid in the baboon: Symptomatology and neuropathological consequences. Ann. Neurol. 8: 501509 .

Monaghan, D. T., and C. W. Cotman (1982) The distribution of $\left[{ }^{3} \mathrm{H}\right]$ kainic acid binding sites in rat CNS as determined by autoradiography. Brain Res. 252: 91-100. 
Nadler, J. V. (1979) Kainic acid: Neurophysiological and neurotoxic actions. Life Sci. 24: 289-300.

Nadler, J. V. (1981) Kainic acid as a tool for the study of temporal lobe epilepsy. Life Sci. 29: 2031-2042.

Nadler, J. V., K. W. Vaca, W. F. White, G. S. Iynch, and C. W. Cotman (1976) Aspartate and glutamate as possible transmitters of excitatory hippocampal afferents. Nature 260: 537539.

Nadler, J. V., B. W. Perry, and C. W. Cotman (1978) Intraventricular kainic acid preferentially destroys hippocampal pyramidal cells. Nature 271: 676-677.

Nadler, J. V., D. A. Evenson, and G. J. Cuthbertson (1981) Comparative loxicity of kainic acid and other amino acids toward rat hippocampal neurons. Neuroscience 6: 2505-2517.

Nicoll, R. A., and B. E. Alger (1981a) A simple chamber for recording from submerged brain slices. J. Neurosci. Methods 4: 153-156.

Nicoll, R. A., and B. E. Alger (1981b) Synaptic excitation may activate a calcium dependent potassium conductance in hippocampal pyramidal cells. Science 212: 957-959.

Prince, D. A. (1978) Neurophysiology of epilepsy. Annu. Rev. Neurosci. 1: 395-415.

Ribak, C. E., J. E. Vaughn, and K. Saito (1978) Immunocytochemical localization of glutamic acid decarboxylase in neuronal somata following colchicine inhibition of axonal transport. Brain Res. 140: 315-332.

Robinson, J. H., and S. Deadwyler (1981) Kainic acid produces depolarization of CA3 pyramidal cells in the in vitro hippocampal slice. Brain Res. 211: 117-127.

Ryan, J., and C. W. Cotman (1978) Electrophysiological action of kainic acid on hippocampal slices. Soc. Neurosci. Abstr. 4: 227.

Schmid, R., J. S. Hong, J. Meek, and E. Costa (1980) The effect of kainic acid on the hippocampal content of putative trans- mitter amino acids. Brain Res. 200: 355-362.

Schwarcz, R., R. Zaczek, and J. T. Coyle (1978) Microinjection of kainic acid into the rat hippocampus. Eur. J. Pharmacol. 50: 209-220.

Schwartzkroin, P. A. (1975) Characteristics of CA1 neurons recorded intracellularly in the hippocampal in vitro slice preparation. Brain Res. 85: 423-436.

Schwartzkroin, P. A., and D. A. Prince (1980) Changes in excitatory and inhibitory potentials leading to epileptogenic activity. Brain Res. 183: 61-76.

Shinozaki, H., and S. Konishi (1970) Actions of several antihelminthics and insecticides on rat cortical neurones. Brain Res. 24: 368 -371 .

Shinozaki, H., and I. Shibuya (1974) Potentiation of glutamateinduced depolarizations by kainic acid in the crayfish opener muscle. Neuropharmacology 13: 1057-1065.

Sloviter, R. S., and B. P. Damiano (1981) On the relationship between kainic acid-induced epileptiform activity and hippocampal neuronal damage. Neuropharmacology 20: 10031011.

Storm-Mathisen, J. (1977) Localization of transmitter candidates in brain: The hippocampal formation as a model. Prog. Neurobiol. 8: 119-181.

Westbrook, G. L., and E. W. Lothman (1983) Cellular and synaptic basis of kainic acid-induced hippocampal epileptiform activity. Brain Res. 273: 97-109.

Wong, R. K. S., and D. A. Prince (1979) Dendritic mechanisms underlying penicillin-induced bursting. Science 204: 1228-1231.

Wong, R. K. S., and R. D. Traub, (1983) Synchronized burst discharge in the disinhibited hippocampal slice. I. Initiation in the CA2-CA3 region. J. Neurophysiol. 49: 442-458.

Zaczek, R., M. Nelson, and J. T. Coyle (1981) Kainic acid neurotoxicity and seizures. Neuropharmacology 20: 183-189. 